\title{
How can health services strengthen support for children affected by overweight and obesity, and their families?
}

\author{
Anthony Zhenga,c and Michelle Cretikos ${ }^{b}$ \\ a Centre for Epidemiology and Evidence, NSW Ministry of Health, Sydney, Australia \\ b Centre for Population Health, NSW Ministry of Health, Sydney, Australia \\ c Corresponding author: Anthony.Zheng@health.nsw.gov.au
}

\section{Article history}

Publication date: March 2019

Citation: Zheng A, Cretikos M. How can health services strengthen support for children affected by overweight and obesity, and their families? Public Health Res Pract. 2019;29(1):e2911903. https://doi. org/10.17061/phrp2911903

\section{Key points}

- Routine growth assessment in children, and family-focused weight management interventions where clinically appropriate, are part of best-practice paediatric care

- All health services should be strengthened to support routine clinical identification and management of affected children and families

- There are a wide range of system-level changes that can be considered to support routine delivery of this care from strengthening growth assessment guidelines to use of electronic information systems for weight management prompts and alerts

\section{Abstract}

More than a quarter of Australian children are above a healthy weight (overweight or obese) and risk significant immediate and future health harms. While childhood overweight and obesity is a complex problem requiring multifaceted solutions, identifying children at risk and preventing these health harms should be a part of good clinical care in all health services. Effective secondary and tertiary prevention is feasible. This paper argues that health services can use serial growth assessment to routinely identify and manage children who are above a healthy weight, just as we might routinely identify and manage hypertension in older patients. We highlight the evidence for the acceptability and effectiveness of family-focused clinical intervention for weight management in children. We also outline system-level changes that health services should consider to enable and support routine clinical identification and management of affected children and their families.

\section{How can health services strengthen support for children affected by overweight and obesity, and their families?}

Overweight and obesity in children is a common, harmful health issue that can often be overlooked when children present to health services with more urgent needs. This complex problem requires multifaceted solutions addressing the family and social environment, but one thing is clear: health services should deliver early, effective secondary prevention and management to children and their families as part of good clinical care.

Health services should routinely identify and manage children who are above a healthy weight (overweight or obese) through routine growth assessment, just as health services routinely identify and manage hypertension in older patients. This requires system-wide change, sustained over many years. However, this is a system investment that our children need, given the significant burden of chronic disease these children face. This paper argues for all health services to implement routine growth assessment 
of children to identify those above healthy weight, and outlines how this can be done in a systematic way.

\section{Prevalence and impacts of childhood overweight and obesity}

In 2014-15, 27.4\% of Australian children aged 5 to 17 years were above a healthy weight and this prevalence has almost tripled over the past three decades., ${ }^{1,2}$ While the upward trend has plateaued at a national level, the distribution of harm remains inequitable. For example, prevalence of overweight and obesity in children continues to increase disproportionately in some states ${ }^{3}$ and in lower socioeconomic and other groups. ${ }^{4}$ Of great concern is the high prevalence of overweight in very young children, with $20 \%$ of 2-4-year-olds classified as being overweight or obese. ${ }^{1}$

The immediate health impacts of overweight or obesity are common and can significantly affect children's physical, psychological and social wellbeing. Common physical consequences include asthma, obstructive sleep apnoea, fatty liver disease, cardiovascular risk factors such as hypertension, insulin resistance and type 2 diabetes (although this remains uncommon). 5,6 Many of these impacts are observed in children and adolescents who are defined as overweight, not obese. ${ }^{7}$

Negative psychosocial impacts are well established. Children who are above a healthy weight have a higher risk of depression, and are more likely to have lower selfesteem and higher body dissatisfaction. 8,9 Their academic achievement in the early years of school is poorer than for students of healthy weight, with consequences that extend into adulthood. ${ }^{10}$

Longer-term harms are significant but remain underappreciated. The majority of children who are obese will become adults with obesity. ${ }^{11}$ In cohort studies, overweight or obesity in adolescence is associated with significantly worse cardiovascular outcomes and a higher all-cause mortality in middle age. ${ }^{12}$

\section{Routine growth assessment: best- practice clinical care for children}

Routine height and weight measurements are important for many reasons. Serial growth assessments should be performed regularly as part of good clinical care because changes in growth trajectory can be the earliest indicator of a range of paediatric health problems. Visual inspection generally underestimates weight status ${ }^{13}$, so accurate measurements should be plotted on growth charts, including the appropriate body mass index (BMI)for-age chart for children aged 2 years or older.

A routinely plotted BMI-for-age chart allows health professionals to raise the sensitive issue of weight with families in an objective, nonjudgemental way. Stigma is a key barrier that frequently prevents discussion of children's weight, but evidence suggests that it is highly acceptable for health professionals to raise the issue with families in a sensitive way. ${ }^{14}$ Routine growth assessments create opportunities to provide family-focused brief lifestyle advice and, over time, help to remove stigma around the issue of a child's weight status and reinforce healthy habits. ${ }^{14}$

\section{Effective secondary and tertiary prevention is feasible}

No obesity strategy can succeed without whole-ofgovernment and whole-of-society approaches to change our social and physical environments, which are characterised by increasing consumption of energy-dense foods with a concurrent increase in sedentary lifestyles.

Being above a healthy weight in childhood causes significant negative impacts on families, on health systems and, most importantly, on children. Health services can and must do more to address this issue. Services should be strengthened to support health professionals to routinely recognise and appropriately manage children who are above a healthy weight using the best available evidence, in the same way that they approach any other chronic health issue with this level of impact. This includes providing brief advice with a focus on positive health behaviours and lifestyles for the whole family. ${ }^{15} \mathrm{~A}$ good example of this advice is the ' 8 for a healthy weight' approach that has been developed for all health professionals to use for children aged 2 years and older. ${ }^{16}$

\section{Clinical weight management interventions}

Health professionals have a responsibility to provide brief health advice, and this advice can be a strong motivator for behavioural change. ${ }^{17}$ Addressing childhood overweight and obesity typically requires whole families to sustain healthier habits and behaviours, and health professionals are trusted to support families in this process. If the child's weight trajectory remains a concern, health professionals should routinely refer children to existing free, evidence based community weight management programs, such as the New South Wales (NSW) Go4Fun healthy lifestyle program for children aged $7-13$ years ${ }^{18}$, and the Get Healthy Service run by NSW Health, which provides free phone-based lifestyle coaching for parents and carers. ${ }^{19}$

Secondary outpatient services are also important referral options. These interventions typically aim, over many weeks, to modify the diet, physical activity and behaviour of school-aged children who are above a healthy weight and, importantly, that of their families. Two recent Cochrane systematic reviews summarise the 
growing evidence for the efficacy and safety of familyfocused lifestyle interventions. ${ }^{20,21}$ Compared to control groups, intervention groups showed a reduction in BMI of up to $1.49 \mathrm{~kg} / \mathrm{m}^{2} 18-24$ months after the intervention, as averaged across 20 studies. ${ }^{20,21}$ These interventions have resulted in few or no adverse events. ${ }^{20,21}$ Referral options for preschool-aged children remain limited to general practitioners and dietitians in most health jurisdictions.

\section{Strengthening health services}

Effective secondary prevention and management requires sustained commitment from health professionals and managers, and there are system-wide approaches that can support this change. Health systems can be strengthened in many different ways, but basic considerations include:

- Reviewing appropriateness of measurement equipment and streamlining clinical workflows

- Strengthening childhood growth assessment policies and guidelines, and implementation support

- Ensuring routine measurement and recording of children's height and weight at the ward or outpatient clinic level

- Using electronic information systems to deliver measurement prompts and weight status alerts

- Developing internet-accessible weight management resources and training for health professionals

- Establishing communities of practice and peer-to-peer support

- Strengthening primary and secondary weight management services and local referral pathways.

Efficient workflow is a key consideration. An important first step is to set up and maintain a 'measurement station' with age-appropriate scales and stadiometers in an appropriate, accessible location so that measurements can be immediately recorded in the electronic medical record. The 'measurement station' pictured in Figure 1 is in a paediatric ward, but a much simpler station will suffice for most services as long as the equipment is appropriately and regularly calibrated and maintained.

Electronic systems can be enhanced so that health professionals are reminded to perform growth measurements, colour-coded BMI-for-age charts are plotted automatically, and alerts are displayed when a child is above or below a healthy weight. Links to referral options and clinical resources that support discussion with families should be easily accessible. Relevant healthcare management and referral information such as primary health network 'HealthPathways' information ${ }^{22}$ should be updated to clearly describe local referral options. Integration with data sources such as My Health Record is an important goal to work towards.

Communities of practice and peer-to-peer support can be established to coordinate changes to workflow. For example, in NSW Health, a working group of local clinical champions from every Local Health District meets regularly to troubleshoot challenges in implementation of routine weight status assessment.

Routine growth assessment can be incorporated into existing workflow processes such as admission checklists in health facilities, community-based assessments, or practice nurse assessments in general practice. Weight and height data can be extracted from electronic medical records as part of clinical audits to identify areas for improvement.

Weight can be a sensitive issue, and health services should provide online and face-to-face training for health professionals in addressing weight issues in children. A number of online modules are freely available, such as the Weight4KIDS modules. ${ }^{23}$ Health services should collaborate with health professional organisations to develop and deliver effective training packages, with newer delivery modes such as webinars likely to prove popular.

Finally, referral options should be strengthened across Australia in light of growing evidence for the benefits of multidisciplinary weight management clinics, and other lifestyle and behavioural interventions. ${ }^{20,21}$ When establishing or upscaling services, it is important to consider the accessibility of services, with communitybased services available outside school hours often more appealing to busy families than traditional hospital-based outpatient clinics. There is great potential for collaboration across services for developing and delivering effective, efficient interventions. For example, clinical resources for group-based family lifestyle clinics could be shared or codeveloped.

Figure 1. Example of a measurement station in a paediatric ward

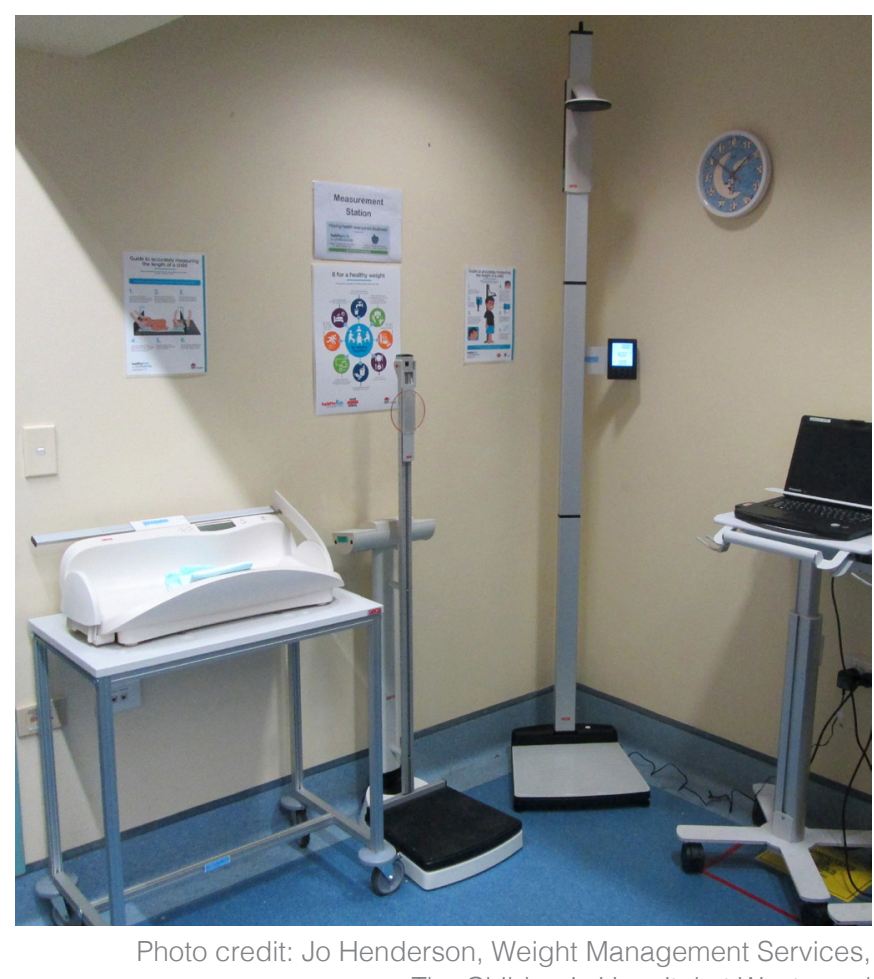

The Children's Hospital at Westmead 


\section{The future of childhood overweight and obesity in Australia}

Childhood overweight and obesity is a complex health issue. The long-term impact will depend on our ability to change the contributing environmental and social factors. This aside, health services cannot ignore the fact that more than one in four children are facing negative health impacts from excess weight, now and in the future.

We have a responsibility to deliver best practice, evidence based care, and we believe it is possible for all health services to make the necessary system changes to enable and support routine clinical identification and management of affected children and their families. We also urge all health professionals to advocate for and play their part in preventing obesity, and in supporting affected children and their families.

\section{Peer review and provenance}

Externally peer reviewed, commissioned.

\section{Competing interests}

None declared.

\section{Author contributions}

AZ drafted the manuscript and MC edited and finalised the manuscript.

\section{References}

1. Australian Bureau of Statistics. National health survey: first results, 2014-15. Canberra: ABS; 2015 [cited 2018 Mar 21]. Available from: www.abs.gov.au/ausstats/ abs@.nsf/Lookup/by\%20Subject/4364.0.55.001 201415 Main\%20Features About\%20the\%20National\%20 Health\%20Survey 3

2. Margery AM, Daniels LA, Boulton TJ. Prevalence of overweight and obesity in Australian children and adolescents: reassessments of 1985 and 1995 data against new standard international definitions. Med J Aust. 2001;174:561-4.

3. Ho NS, Olds T, Schranz N, Maher C. Secular trends in the prevalence of childhood overweight and obesity across Australian states: a meta-analysis. J Sci Med Sport. 2017;20(5):480-8.

4. O'Dea JA, Chiang H, Peralta LR. Socioeconomic patterns of overweight, obesity but not thinness persist from childhood to adolescence in a 6-year longitudinal cohort of Australian schoolchildren from 2007 to 2012. BMC Public Health. 2014;14(1):1-20.

5. Lobstein T, Baur L, Uauy R. Obesity in children and young people: a crisis in public health. Obes Rev. 2004;5(S1):4-85.
6. Ebbeling CB, Pawlak DB, Ludwig DS. Childhood obesity: public-health crisis, common sense cure. Lancet. 2002;360(9331):473-82.

7. Denney-Wilson E, Hardy LL, Dobbins T, Okely AD, Baur LA. Body mass index, waist circumference and chronic disease risk factors in Australian adolescents. Arch Pediatr Adolesc Med. 2008;162(6):566-73.

8. Strauss RS. Childhood obesity and self-esteem. Pediatrics. 2000;105(1):e15.

9. French SA, Story M, Perry CL. Self-esteem and obesity in children and adolescents: a literature review. Obes Rev. 1995;3(5):479-90.

10. Datar A, Sturm R, Magnabosco JL. Childhood overweight and academic performance: national study of kindergartners and first-graders. Obes Res. 2004;12(1):58-68.

11. Juonala M, Magnussen CG, Berenson GS, Venn A, Burns TL, Sabin MA, et al. Childhood adiposity, adult adiposity, and cardiovascular risk factors. N Engl J Med. 2011;365(20):1876-85.

12. Twig G, Yaniv G, Levine H, Leiba A, Goldberger N, Derazne $\mathrm{E}$, et al. Body-mass index in 2.3 million adolescents and cardiovascular death in adulthood. N Engl J Med. 2016;374:2430-40.

13. Hardy LL, Mihrshahi S, Drayton BA, Bauman A. NSW schools physical activity and nutrition survey (SPANS) 2015: full report. Sydney: NSW Department of Health; 2016 [cited 2018 Mar 21]. Available from: www.health. nsw.gov.au/heal/Publications/spans-2015-full-report.PDF

14. Dawson AM, Brown DA, Williams SM, Taylor BJ, Ross J, Taylor RW. Parental reactions to weight screening in young children: a randomized controlled trial. Paediatr Obes. 2016;13(11):639-46.

15. National Health and Medical Research Council. Clinical practice guidelines for the management of overweight and obesity in adults, adolescents and children in Australia. Melbourne: NHMRC; 2013 [cited 2018 Mar 21]. Available from: nhmrc.gov.au/about-us/publications/ clinical-practice-guidelines-management-overweightand-obesity

16. Healthy kids for professionals: weight management resources for professionals. Sydney: NSW Health; 2019. 8 for a healthy weight [cited 2018 Mar 21]; [about 3 screens]. Available from: pro.healthykids.nsw.gov.au/ advise

17. Aveyard P, Lewis A, Tearne S, Hood K, ChristianBrown A, Adab P, et al. Screening and brief intervention for obesity in primary care: a parallel, two-arm, randomised trial. Lancet. 2016;388(10059):2492-500.

18. Go4Fun: healthy active happy kids. Sydney: New South Wales Ministry of Health; 2013 [cited 2019 Feb 4]. Available from: go4fun.com.au

19. Get healthy: information and coaching service. Sydney: New South Wales Health Department; 2019 [cited 2019 Feb 4]. Available from: www.gethealthynsw.com.au 
20. Mead E, Brown T, Rees K, Azevedo LB, Whittaker V, Jones $\mathrm{D}$, et al. Diet, physical activity and behavioural interventions for the treatment of overweight or obese children from the age of 6 to 11 years. Cochrane Database Syst Rev. 2017(6):CD012651.

21. Al-Khudairy L, Loveman E, Colquitt JL, Mead E, Johnson RE, Fraser H, et al. Diet, physical activity and behavioural interventions for the treatment of overweight or obese adolescents aged 12 to 17 years. Cochrane Database Syst Rev. 2017(6):CD012691.
22. NSW Health. Flow chart for weight assessment and management in children above a healthy weight. Sydney: New South Wales Health Department; 2017 [cited 2019 Feb 4]. Available from: pro.healthykids.nsw.gov.au/wpcontent/uploads/2017/04/HNSW_223684_Model-of-CareFlyer_Web_FA2.pdf

23. Weight4KIDS e-learning portal. Sydney: LearnUpon; 2018 [cited 2018 Mar 21]. Available from: weight4kids. learnupon.com

\section{Copyright: (c) (1) (2)}

(C) 2019 Zheng and Cretikos. This article is licensed under the Creative Commons Attribution-NonCommercial-ShareAlike 4.0 International Licence, which allows others to redistribute, adapt and share this work non-commercially provided they attribute the work and any adapted version of it is distributed under the same Creative Commons licence terms. See: www.creativecommons.org/licenses/by-nc-sa/4.0/ 